\title{
PARADOXOS DA IDENTIDADE: A POLÍTICA DE ORIENTAÇÃO SEXUAL NO SÉCULO XX ${ }^{1}$
}

\author{
Míriam Adelman \\ Universidade Federal do Paraná
}

\begin{abstract}
RESUMO
Trabalhando com a perspectiva do construcionismo social sobre a sexualidade, este artigo tem por objetivo problematizar o surgimento das identidades sexuais modernas. Identifico, por um lado, a "invenção" da homossexualidade (e, portanto, da heterossexualidade) na produção discursiva da sociedade vitoriana. Por outro lado, discuto a forma em que essa nova categoria torna-se base de uma luta política que reivindica a diversidade sexual, enfocando principalmente a evolução de políticas de orientação sexual na sociedade norte-americana do século $X X$.
\end{abstract}

PALAVRAS-CHAVE: política sexual; identidades sexuais; novos movimentos sociais.

\begin{abstract}
"Se, como suspeito, a bissexualidade não é somente outra orientação sexual, e sim uma sexualidade que desfaz a orientação sexual como categoria, uma sexualidade que ameaça e questiona a fácil dualidade de hetero e gay [...] e mesmo, através de seus significados biológicos e fisiológicos, as categorias de masculino e feminino, então a busca de significado para a palavra "bissexual" oferece uma lição diferente. Em vez de dar nome a uma minoria invisível, mal percebida, que agora encontra seu lugar ao sol, a categoria "bissexual” passa a estar, como os próprios bissexuais, em todo lugar e em lugar nenhum. Resumindo, não existe um "realmente". A questão de saber se alguém era "realmente" hetero ou "realmente" gay deixa de reconhecer a natureza da sexualidade, que é fluída, não fixa, ainda que complexa. A descoberta erótica da bissexualidade é o fato de ela revelar que a sexualidade é um processo de crescimento, transformação e surpresa, e não um estado conhecível e estável".
\end{abstract}

Marjorie Garber (1997)

"Nossa cultura procura causas [...] seria tão fácil se [a explicação da orientação sexual] se desse na biologia. Vejo isto como muito atraente para as pessoas que não querem ter preconceitos [...] A ciência é nosso Deus, de tal maneira que se a Ciência aprovasse [a homossexualidade], seria como se Deus desse sua aprovação".

Jane Hohenberger, universitária americana (apud Jan Clausen, 1997)

\section{INTRODUÇÃO}

$\mathrm{Na}$ atualidade, fala-se muito sobre "a diferença", a diversidade e o direito de todos à cidadania - parece, de fato, que qualquer um pode apropriar-se desse discurso, que não só é agradável, humanitário etc., mas também aparentemente muito fácil de casar com o discurso liberal da atual sociedade, na qual há um mercado para

1 Uma primeira versão deste trabalho foi apresentada como palestra proferida para a Pride 99 (Semana de Orgulho Gay), em Curitiba, em 22/06/1999, a convite do Grupo Dignidade de Curitiba (Paraná). tudo, e portanto, um espaço "para todos". Os excluídos são, por esse discurso, muito rapidamente incluídos, e todos caminhamos juntos na trilha da igualdade, numa sociedade que está "evoluindo".

Mas pouco se sabe, e pouco se quer saber, sobre as relações de poder que estão na base da lógica da exclusão; como alguns grupos foram, de fato, excluidos do poder, da riqueza, do status social, e quais foram as lutas históricas - ainda longe de serem concluídas - que nos trouxeram até este momento, no qual, pelo menos, tais lutas tornaram-se "legítimas". Minha intenção aqui será, neste sentido, responder a uma série de perguntas sobre o poder e a construção das "sexualidades" 
ou identidades sexuais, partindo da idéia de que a sexualidade dá- se no âmbito da cultura - portanto, não há uma "sexualidade natural" nem uma forma de praticar a sexualidade mais natural do que outra; há só construções sociais e históricas da sexualidade, que implicam sempre determinados tipos de encontro com o poder ${ }^{2}$. Como então entender a construção histórica de sexualidades marginalizadas, de pessoas e grupos que são oprimidos pela maneira que vivem sua sexualidade? $\mathrm{O}$ que isso diz de específico sobre a sociedade ocidental moderna? Como e por que surgem, na segunda metade deste século, movimentos sociais e políticos articulados a partir da identidade sexual? Qual a relação desses movimentos com os outros novos movimentos sociais do mesmo momento histórico?

Trata-se de refletir sobre uma época que reúne as características de grande politização da sexualidade, que - como aponta a antropóloga norte-americana Gayle Rubin ${ }^{3}$ - representa a intensificação do caráter sempre político dessa esfera de prática humana: "O âmbito da sexualidade [...] tem sua própria política interna, iniqüidades e modos de opressão. Como acontece com outros aspectos do comportamento humano, as formas institucionais concretas da sexualidade humana, num espaço e tempo determinados, são produto da atividade humana. Elas estão repletas de conflitos de interesse e manobra política, tanto de natureza proposital quanto circunstancial. Nesse sentido, o sexo é sempre politizado. Há, porém, períodos históricos nos quais a sexualidade

\footnotetext{
2 Uso aqui o termo poder no sentido da dominação exercida (e/ou o potencial historicamente adquirido para exercê-la) por grupos vinculados à preservação da ordem social existente e os privilégios que eles mantêm dentro desta. Trata-se de um poder arraigado nas instituições sociais que incluem mas não se limitam ao Estado, e de relações de poder que se manifestam e geram resistência em diversos espaços institucionais assim como no cotidiano. Considero que a sociedade moderna caracteriza-se por uma forma histórica de relações de poder baseada na imbricação de hierarquias de classe, raça e gênero, que à sua vez forjam determinadas formas de organizar a sexualidade, que incorporam tanto hierarquias de gênero quanto padrões burgueses de organização familiar. Existe já uma ampla literatura foucaultiana e feminista que aprofunda essas questões.

3 Pioneira feminista com grandes contribuições teóricas na área de gênero e de sexualidade.
}

é mais contestada e abertamente politizada. Nesses períodos, o domínio da vida erótica é efetivamente re-negociado" (RUBIN, 1998, p. 100) ${ }^{4}$.

Sabemos, em grande parte a partir do nosso encontro com ideologias ou visões do mundo advindas das grandes religiões ocidentais (o catolicismo, o judaísmo e o protestantismo), que o Ocidente tem um "investimento histórico" num tipo de sexualidade: aquela que permite a organização social a partir de um determinado tipo de família, baseada num casal heterossexual e monogâmico e que restringe ou privilegia a prática sexual orientada para a procriação. Também sabemos, em grande parte a partir da popularização das idéias de Freud, que as possibilidades humanas de expressão sexual se chocam constantemente contra os limites colocados por essas formas institucionalizadas de prática sexual; o pensamento freudiano sugere que as instituições que criamos nos limitam, e nos limitam de maneiras que instituem repressão, violência, mal-estar individual e coletivo. E a nossa história recente afirma que os mesmos processos de institucionalização da sexualidade estão sempre em transformação, e são mutáveis também porque nós os alteramos no nosso dia-a-dia, na atividade política, social e cultural.

\section{O PODER DA PALAVRA: A PRODUÇÃO DISCURSIVA NA CRIAÇÃO DAS IDEN- TIDADES SEXUAIS MODERNAS}

Nas primeiras fases da formação da sociedade moderna $^{5}$, se o exercício da sexualidade era normativamente restrito ao âmbito do casamento monogâmico e subordinado aos imperativos da procriação, por outro lado, não se verificava tão grande interesse na identificação de outras práticas ou formas das pessoas viverem sua sexualidade. A sexualidade das mulheres da elite era, em todo caso, a mais vigiada. Para muitos outros grupos sociais, havia uma margem de tolerância no exercício da sexualidade, embora em nível simbólico as práticas mais diversificadas desses grupos servissem para a classe dominante se apre-

\footnotetext{
4 Tradução minha do inglês.

5 Trabalho aqui principalmente com dados sobre a sociedade norte-americana, que é a que melhor conheço e para a qual existe já amplo material sobre a história das sexualidades.
} 
sentar como "moralmente superior"6. Havia, entre outras coisas, mulheres e homens que se relacionavam sexualmente com parceiros do mesmo sexo que podiam tornar-se alvo de reprovação ou punição por transgressão sexual; mesmo assim, esses atos não os marcavam como pessoas inerentemente ou fundamentalmente diferentes dos outros. Quer dizer, o comportamento sexual não constituía um marcador ou "determinante" da personalidade (ou "identidade") individual (D'EMILIO, 1983).

Isso mudou somente no final do século XIX, momento a partir do qual algumas pessoas passam a serem identificadas como "homossexuais", principalmente por conta de um novo discurso médico-científico preocupado com o estudo e classificação das patologias ${ }^{7}$. Os primeiros estudos tentaram identificar as manifestações e "causas" da homossexualidade com um interesse na terapização e normatização da vida sexual, projeto que formava parte do movimento de higiene social dirigido ao controle e à regulação da vida das massas urbanas. E vale a pena lembrar que não só os homossexuais eram alvo desse movimento: de fato, as campanhas de higiene social pertenciam a um momento histórico que endossava a expressão sexual quando ela acontecia consagrada pelo vínculo matrimonial, e a estigmatizava em qualquer outro âmbito ou contexto. Praticava-se uma vigilância moral no que dizia respeito a todo tipo de comportamento sexual "diferente", porém alguns consideravam-se mais transgressores do

\footnotetext{
6 Entre a população trabalhadora, a instabilidade econômica dificultava o estabelecimento de laços matrimoniais mais estáveis, situação que já a sujeitava à acusação de "promiscuidade". Os negros norte-americanos, cuja cultura sexual se desenvolveu de maneiras muito menos padronizadas do que a população branca e de "classe média”, foram julgados a partir de um discurso que unia elementos de pensamento baseados nas noções da superioridade européia, da inferioridade feminina e da sexualidade exclusivamente procriativa.

7 Parte de um processo que se desenvolve ao longo do século XIX, da criação das instituições do "poder disciplinar" - novas formas coletivas de controle sobre o sujeito e sua corporalidade. Essas instituições envolvem tanto novos saberes quanto novas técnicas de controle; no caso da sexualidade, trata-se da produção de um discurso médico-científico que veicula técnicas de intervenção e cria os espaços particulares para tal intervenção, particularmente, o hospital e a clínica. Ver Hall (1998) sobre os trabalhos de Michel Foucault.
}

que outros. Aquilo que hoje conhecemos por "o duplo padrão" - a aplicação de critérios de moralidade diferenciados - criava tolerâncias e punições diferenciados que envolviam questões de gênero, classe e raça. Por exemplo, permitia aos homens uma licença para atividade heterossexual fora do casamento que era negada às mulheres. A prostituição de mulheres de camadas populares, desde que mantida dentro de certos limites, era nessa época menos preocupante do que a demonstração de um interesse sexual "forte" ou "precoce" numa menina adolescente ou numa mulher de classe mé$\mathrm{dia}^{8}$, e tal como a homossexualidade, a sexualidade feminina era sempre susceptível de suspeita.

A intensa produção discursiva sobre a sexualidade não era monolítica nem livre de contradições. A "sexologia", nova ciência do século XIX que se debruçou sobre a tarefa positivista de classificar os "tipos" e comportamentos sexuais, contribuiu para produzir a homossexualidade. Em grande parte, isto significou produzi-la como condição patológica. No entanto, houve também uma abordagem sexológica que tentava justificá-la, argumentando que se tratava de uma natureza diferente que algumas pessoas possuíam, contra a qual (sendo esta "natural") não haveria porque lutar ${ }^{9}$. Foi, pois, nesse momento que se instituiu o "personagem" do homossexual ${ }^{10}$, figura que então entrou num cenário

\footnotetext{
$8 \mathrm{Na}$ ideologia vitoriana, a crença de que as mulheres eram muito mais maternais do que sexuais não era suficiente para eximi-las da vigilância cotidiana, que se dava em estreita relação com a instituição da medicina. Os diagnósticos e o tratamento da "ninfomania" no século XX é uma clara demonstração disso: mulheres que mostravam um desejo sexual ativo poderiam tornar-se alvo de intervenções cirúrgicas cruéis (como a remoção do útero, dos ovários, ou a clitorodetomia), que supostamente iriam "curar" sua condição (ver GRONEMAN, 1994).

9 Como Clausen argumenta, "This historical ambiguity sex as the prisoner of science versus science as sex's rescuer has never been resolved. It accounts for some of the intensity of debates between social constructionists, who, like Foucault, bave often stressed the sinister role of science, and essentialist advocates of biological research, who hope that scientific understanding can belp demystify and destigmatize samesex behavior” (CLAUSEN, 1997, p. 66).

10 Parece que num primeiro momento enfoca-se mais o homossexual masculino. Essa visibilidade aparentemente pode estar relacionada com o fato da relativa exclusão das mulheres da esfera pública (e portanto, uma vida
} 
onde sua própria existência, e seu corpo, se tornariam objeto de pesquisa, escrutínio e vigilância, bem como de disputas sobre sua representação.

Entre os trabalhos hoje mais notórios está o livro escrito em 1894 pelo austríaco Krafft-Ebing, exemplo da nova perspectiva médica que buscava estudar "as condições psicológicas e patológicas da vida erótica". Partia da premissa que o desejo sexual era em si perigoso para a civilização, sempre beirando a patologia e a doença, uma força que se não controlada ameaçaria a ordem social sobre a qual a superioridade da cultura européia teria se estabelecido (BRISTOW, 1997). Como a maior parte dos seus contemporâneos, a homossexualidade era para ele uma condição congênita. Mesmo assim, ele não deixava de considerar que existiam fatores sociais ou circunstâncias específicas que poderiam conduzir as pessoas às práticas desviantes, mencionando especificamente que as mulheres poderiam ter motivos sociais para não desejar a companhia dos homens (idem, p. 32-33).

O alemão Karl Heinrich Ulrichs, autor de 12 livros sobre sexualidade escritos entre 1864 e 1879 e cujo objetivo era provar a "naturalidade" das relações sexuais entre homens, pensava que essa naturalidade baseava-se numa inversão sexual "natural": a existência de pessoas com corpos masculinos mas possuidores de um desejo sexual "feminino". A concepção dele era a mesma que caracteriza a grande parte do trabalho dos sexólogos da época: como, para eles, a sexualidade não poderia ser pensada senão a partir do $d i$ morfismo sexual (e a partir da polaridade de gênero), a homossexualidade tornava-se uma espécie de discordância entre subjetividade e corporalidade sexuais (idem, p. 24)

Freud, que as vezes é visto como "inimigo" pelos movimentos homossexuais, talvez tenha sido mal-conhecido, mais por conta do pensamento de alguns dos seus seguidores do que através do pensamento, de fato ambivalente, dele mesmo (CLAUSEN, 1997). Sua perspectiva representou um grande avanço em relação à sexologia da época

íntima menos acessível ao olhar científico, principalmente antes da invenção da escuta analítica); deve também sugerir alguma coisa sobre a preocupação dos primeiros sexólogos, sendo eles mesmos, na sua grande maioria, de sexo masculino. vitoriana, já que abandonou o esquema da "inversão sexual" e mudou o enfoque da biologia para a cultura. Ele mesmo identificou, como "uma das óbvias injustiças da vida social" o fato de a cultura exigir de todos um mesmo e único tipo de comportamento sexual. Embora se possa identificar atitudes contraditórias de Freud em relação à homossexualidade, sua teoria ofereceu uma grande contribuição para o pensamento crítico, na medida em que afirmava que a heterossexualidade, tanto como a homossexualidade, requeria explicação, e que não poderia ser entendida simplesmente como o resultado "natural" dos imperativos de reprodução humana. Colocou a bissexualidade "no centro do seu aparelho explicativo", sugerindo que todo ser humano é, num nível inconsciente, prédisposto à bissexualidade (idem, p. 70-71), quer dizer, um "livre jogo" das possibilidades eróticas, que fora do alvo das pressões e tabus culturais, não estaria atrelado à escolha de um parceiro ou objeto de gênero específico. A heterossexualidade se aprendia, através de uma travessia edípica muitas vezes penosa ${ }^{11}$.

O que fica claro é que, a partir da segunda metade do século XIX, iniciou-se um processo de intensa politização da sexualidade, que de fato levou à criação das identidades sexuais modernas, e que mostrou que as questões de sexualidade, imbricadas com as relações de poder de gênero, classe e raça, formavam parte de um conjunto de relações sociais sujeitas à contestação. Como já sugeri, a "proliferação dos discursos" vinculouse num primeiro momento aos movimentos de higiene social, através dos quais os novos grupos profissionais de classe média não só "trabalhavam a serviço" de uma classe dominante preocupada com o controle das massas urbanas, senão que se guiavam por seus próprios interesses profissionais na criação - e gerenciamento - de novos saberes. Mas as preocupações de tais grupos refletiam ao mesmo tempo as novas condições de vida dos grandes centros urbanos, onde a expansão do mercado de trabalho e consumo e as mudanças na ordem de gênero criaram novos problemas, novas personagens e o cenário de novas lutas políticas. Birken considera que, nesse processo, "As liberdades oferecidas pelos princípios de mercado

11 Poder-se-ia discutir a noção do instintivo ou do "présocial” em Freud, embora não seja este o espaço para tal discussão. 
emergentes criaram sujeitos individuais cujas idiossincrasias poderiam ameaçar a ordem social como um todo. A uma crescente ênfase na autonomia vinculou-se uma demanda correspondente por mais leis regulatórias para controlar a potencial anarquia desencadeada pela proliferação dos desejos individuais" (apud BRISTOW, 1997, p. 57-58) ${ }^{12}$. O espaço maior para a expressão desses "desejos individuais" poderia, pois, significar mais espaço para a transgressão.

Pode-se dizer, então, que a mesma configuração moderna do indivíduo abriu espaço para a afirmação de uma identidade sexual individual, mesmo que esta se construísse como ameaça às normas ou aos princípios da ordem de sexo/gênero vigente. Essa identidade encontrava apoio em um mercado de consumo que estimulava a busca de estilos de vida diferenciados num mundo que permitia e incentivava, de certa forma, a construção de uma identidade pessoal fora do âmbito do trabalho (ZARETSKY, 1976). Porém, ao mesmo tempo, essa construção de novas identidades também gerou fortes reações por parte de pessoas e instituições afetadas pelo que poderia ser percebido como um desafio a seu poder ou legitimidade, que assim se empenharam em impor diversas formas de controle (legislação, policiamento direto e indireto etc.) ou exercer um "poder disciplinar" sobre os transgressores. Isso criou um cenário para novas batalhas sobre politica sexual.

III.OUT OF THE CLOSET AND INTO THE STREETS: O SURGIMENTO DO MOVIMENTO DE LIBERTAÇÃO HOMOSSEXUAL NOS EUA

Os historiadores americanos Freedman e D'Emilio sugerem a identificação, para cada época histórica, de três elementos fundamentais que juntos mostram como uma sociedade constrói e organiza a sexualidade: os significados (representações) sexuais (sexual meanings), os sistemas de regulação ou controle da sexualidade (systems of sexual regulation) e a politica sexual (sexual politics) (D'EMILIO \& FREEDMAN, 1988, p. $\mathrm{XV})$. Isso nos permite identificar concretamente os mecanismos de operação das relações de poder/ sexualidade em diversos momentos. Se, por exemplo, na época colonial nos EUA os "significados

12 Tradução minha. sexuais" desqualificavam a sexualidade fora de sua relação com a procriação e o sistema de regulação da sexualidade centrava-se na igreja e na comunidade, no século XIX destaca-se a forma em que o sistema de regulação se deu pela medicalização da sexualidade e o vínculo das instituições médicas com o Estado. No século XX surgiu e fortaleceu-se a representação da sexualidade como fonte de prazer e expressão individual, vinculada à identidade pessoal e ao seu novo "aliado", o mercado. As formas "tradicionais" (igreja, família, comunidade) e "modernas" (o Estado, a medicina e a psiquiatria) de regulação da sexualidade começaram a ser contestadas ativamente, através da política sexual de diversos grupos que sofriam a ação desses sistemas: em particular, as mulheres, as pessoas homossexuais e bissexuais, e os jovens.

A gênese de novas formas de política sexual tomou seu grande impulso das novas formas associativas e culturais da vida urbana, e da forma que o mercado de trabalho individualizava, até certo ponto, a questão da sobrevivência econômica, diminuindo portanto o poder das famílias sobre seus membros. A nova mulher do início do século vinte é um exemplo do sujeito baseado nessa nova autonomia: trata-se da representação cultural de uma mulher engajada na esfera pública, ativa em relação ao trabalho, ao lazer e à sexualidade. Embora essa imagem esteja muito distante da realidade da grande parte das mulheres da época, indica que de fato já estava havendo uma mudança em relação aos padrões vitorianos de domesticidade e subordinação familiar femininas.

Também em relação às homossexualidades, as grandes cidades oferecerem um espaço de convivência onde pessoas com interesse erótico em outras do mesmo sexo podiam se conhecer e começar a construir uma identidade. No seu livro sobre a construção de uma "minoria homossexual" nos Estados Unidos, de 1940 a 1970, o historiador John D'Emilio se debruça sobre os fatores que, pouco a pouco, foram convergindo até poder emergir essa "minoria", passando de subcultura até constituirse como grupo com uma identidade política própria, e mostra como precisou de um cenário social maior propício para sua irrupção como movimento social capaz de influir na modificação política dos significados e sistemas de regulação sexuais da sociedade americana.

Segundo D'Emilio, nas grandes cidades americanas do período entre as duas guerras mundiais, 
criou-se uma subcultura gay que permitiu que algumas pessoas saíssem do isolamento, do closet, como costuma dizer-se, e desenvolvessem uma identidade coletiva. No entanto, a participação nesse tipo de milieu ainda constituía mais a exceção do que a regra. Para a maior parte dos homossexuais, sua identidade continuava sendo um segredo bem vigiado, com o risco de sofrer grande estigma social, rejeição familiar, marginalização social e perda do emprego. Para muitos, o "segredo" era acompanhado por sentimentos de culpa, pela internalização da noção - ainda prevalecente na sociedade - de que os homossexuais eram portadores de uma condição individual patológica; neste contexto, uma vida pautada na auto-estima e no bemestar psicológico tornava-se muito difícil.

O desequilíbrio temporário provocado pela Segunda Guerra Mundial teve como uma das suas conseqüências a desestabilização de formas convencionais de organização da vida cotidiana e familiar. Como é amplamente sabido, o pós-guerra foi um momento de ingresso maciço de mulheres no mercado de trabalho, incluindo postos na indústria pesada que noutros momentos eram considerados como trabalho inapropriado para as mulheres. A esse tipo de "desordem" na ordem de gênero juntavam-se outras situações de conjuntura, como a criação de espaços de interação exclusivamente femininos e masculinos como aqueles proporcionados pelas funções militares ${ }^{13}$, operando como estímulo para uma subcultura gay que ainda precisava de espaços escondidos ou protegidos para poder se manifestar.

No entanto, os tempos eram ainda muito conservadores. As primeiras associações sócio-políticas de pessoas que se identificavam por sua orientação sexual se formaram na década dos 50 - passo importante num processo gradativo de formulação de uma nova identidade coletiva - em pleno pósguerra macarthista ${ }^{14}$. $\mathrm{O}$ mesmo zelo macarthista de denunciar a "ameaça homossexual" teve, porém, efeitos contraditórios: se, por um lado, conseguiu amedrontar pessoas cuja vontade era minimizar o estigma da homossexualidade, preferindo

\footnotetext{
13 Como o foram os quartéis e os alojamentos militares, os longos períodos de confinamento em bases, navios etc.

14 O primeiro grupo organizado em defesa dos homossexuais , The Mattachine Society, foi formado em 1950, numa pequena reunião de homens homossexuais, incluindo o corajoso organizador comunista Harry Hays. O livro
}

viver no anonimato de uma condição clandestina, teve, por outro lado, o papel de incentivar a radicalização dos processos de formação de identidade coletiva. Nas palavras de D'Emilio, “A opressão estigmatizada da década de 1950 exerceu influências contraditórias sobre os gays. Ao condenar repetidamente o fenômeno, polemistas 'anti-gay' romperam o silêncio que existia em torno do tema da homossexualidade. Portanto, ampliaram-se significativamente os recursos com os quais as lésbicas e os homossexuais dispunham para dar significado a sentimentos que de outra forma ficavam pouco compreendidos. Os ataques aos homens e mulheres apressou a articulação de uma identidade homossexual e divulgou o fato da sua existência, como uma população numerosa. Ironicamente, o esforço de erradicar os homossexuais da sociedade norte-americana facilitou que os mesmos se encontrassem" (p. 52) $)^{15}$.

Durante os anos que se seguiram, houve resistência à perseguição e a subcultura gay se manteve através da vida social dos bares - único espaço público de encontro para mulheres e homens homossexuais - e de alguns grupos políticos, assim como jornais e revistas produzidos dentro e para a comunidade gay, de circulação local e nacional.

As comunidades que iam se formando tinham também suas rachaduras. As divisões mais importantes davam-se entre os que colocavam como meta conquistar o sossego de uma "vida normal" e os que reivindicavam a diferença, questionando com isso a mesma normatização da vida social. Quer dizer, para alguns, tratava-se mais de uma questão individual, das possibilidades de serem socialmente aceitos como qualquer outro cidadão respeitável. Para outros, era hora de articular

\footnotetext{
de D’Emilio conta detalhadamente a história do surgimento, evolução e declínio deste e de outros grupos com os quais se inicia o movimento norteamericano de libertação homossexual. Em relação a este período, é importante ressaltar que a histeria macarthista mobilizava os sentimentos da população norte-americana contra o "espectro" tanto dos comunistas como dos homossexuais, representando ambos como grande ameaça à poderosa nação americana. A caça-às-bruxas da época contra intelectuais e artistas da esquerda norte-americana é, talvez, mais conhecida hoje do que a história dos que sofreram perseguição e perda do emprego por causa da sua orientação sexual.

15 Tradução minha.
} 
politicamente a relação de sua condição como grupo oprimido como parte de uma crítica à sociedade norte-americana da época.

Outra divisão que começou despontar era a de gênero, na medida em que as lésbicas começaram a enxergar-se na sua especificidade como mulheres. Embora a condição comum de serem homossexuais numa cultura heterossexista pudesse unir homens e mulheres, as lésbicas ainda tinham que encarar as dificuldades geradas pela subordinação social feminina, o que criou para elas uma problemática particular. A sociedade "pós-vitoriana" continuava ditando regras sobre o comportamento sexual e sobre espaços sociais "apropriados" para as mulheres. Os limites que se estabeleciam para o acesso feminino ao mercado de trabalho e às profissões faziam que a questão da sobrevivência econômica e as possibilidades para uma vida independente se tornassem mais difíceis para as mulheres homossexuais do que para os homens (idem, p. 93). Por outro lado, os homens homossexuais não se isentavam das influências da ideologia da superioridade masculina, o que também parece ter sido um fator que conduziu à organização autônoma das mulheres.

No final dos anos 60 , as condições da sociedade americana já tinham se transformado de tal maneira que, do clima inóspito de prosperidade e conservadorismo do pós-guerra, emergiu uma nova conjuntura de conflito social, campo fértil para toda uma série de novos movimentos sociais ${ }^{16}$, entre os quais iriam se destacar a "segunda onda feminista" e um renovado e combativo movimento pela libertação gay que, com certeza, pode se considerar como o herdeiro do trabalho feito em décadas anteriores pelos pioneiros do

\footnotetext{
16 Embora este não seja o espaço para discorrer sobre a erupção dos novos movimentos sociais nos EUA e na Europa na década de 60, cabe ressaltar alguns antecedentes e fatores significativos. Nos EUA, desde os anos 50 já vinha crescendo com grande força o civil rights movement, movimento pelos direitos civis dos negros norte-americanos. A onda de lutas contra o imperialismo norte-americano e o neocolonialismo europeu em várias partes do "terceiro mundo" também estimularam o protesto dos jovens americanos contra o envolvimento norte-americano no Vietnã, que se juntou a um movimento contracultural entre as novas gerações de rejeição do American way of life, elaborando uma crítica anticapitalista, anticonsumista, e que resgatava a dignidade e os direitos de todas as "minorias" e grupos que a sociedade norte-americana marginalizava.
}

movimento homossexual. Aliás, ele também representava uma ruptura com o mesmo, destacando-se agora por sua radicalidade, quer dizer, pela forma que incorporava a nova "cultura de protesto" dos anos 60 (idem, p. 223), levando suas reivindicações para a rua onde, com muito barulho e à plena luz do dia, expunha sua diferença, com o mesmo orgulho que outros grupos "minoritários" se faziam ver e ouvir.

Considera-se como início simbólico desse movimento a revolta de Stonewall, acontecido numa noite de verão em 1969 , na cidade de Nova Iorque. Nessa ocasião, o assédio - prática comum dos policiais que costumavam invadir os bares gays - gerou uma violenta resistência que veio a catalizar a formação de um movimento nacional de libertação homossexual. Que isso pudesse acontecer foi de fato um sinal dos tempos: outros movimentos sociais já vinham trilhando os caminhos da confrontação direta e desenvolviam uma filosofia que incorporava a organização das bases, a contestação política e uma política cultural baseada na reivindicação da identidade.

A grande mudança foi, de fato, ter se transformado de uma subcultura estigmatizada, circunscrita à clandestinidade e obrigada a agir defensivamente, em um movimento que elaborava abertamente uma crítica às relações sociais com que se oprimia e marginalizava a homossexualidade. Como movimento, as atividades eram amplas e diversas: iam desde community building, quer dizer, a construção de uma comunidade alternativa, com organização política, social e empresarial próprias; incluíam a atividade cultural, através da qual a experiência subjetiva de ser homossexual era reivindicada, legitimada e divulga$\mathrm{da}$; e passavam pelas estratégias voltadas à reforma das instituições políticas existentes, como por exemplo as campanhas contra a discriminação no trabalho e através da lei.

Foi, e tem sido, uma longa batalha, um caminho de avanços e retrocessos: se, por exemplo, um dos primeiros sucessos foi levar o governo federal a eliminar sua política de não dar emprego aos homossexuais, e conseguir, junto com outros "grupos minoritários", uma legislação geral contra a discriminação, na área do direito familiar prevalece a noção da família baseada no casamento heterossexual que gera filhos, impedindo o avanço e a conquista da legitimidade para outras formas de viver a família. Faz tempo que as 
instituições de "poder disciplinar" da medicina foram obrigadas a retirar suas posições oficiais que equiparavam a homossexualidade à doença e aos distúrbios psiquiátricos, porém nas escolas públicas, qualquer tentativa, por tímida que seja, de "democratizar" o ensino para incluir o tema da homossexualidade como uma possibilidade humana entre outras, topa com resistência que pode tornar-se violenta ${ }^{17}$. A forma em que a orientação sexual se entrelaça com outras relações sociais de gênero, raça e classe social - também age sobre os processos de estigmatização ou marginalização que continuam operando: basta pensar na situação de uma mulher negra e lésbica, sem profissão lucrativa e com filhos para criar, e compará-la com a de um homossexual branco, com uma profissão prestigiosa e dinheiro para viagens e lazer.

No entanto, não é este o espaço para fazer um balanço mais detalhado da situação atual, senão para concluir, retomar aqui os três elementos acima discutidos - sistemas de regulação sexual, significados e política sexuais - que neste limiar de século continuam como terrenos de grande conflito. Como sugeri acima, tanto os sistemas de regulação "tradicionais" quanto os "modernos", que em si coexistem conflituosamente, vêm sendo pressionados e modificados pelos diversos atores e movimentos sociais da atualidade. As atividades das feministas e do movimento gay, a influência do mercado e a mídia, as ações das igrejas e dos grupos tradicionalistas, têm todos um papel na formulação de representações e de políticas de sexualidade. O século está chegando a seu fim, num certo vaivém de posicionamentos e lutas pela hegemonia, sem a certeza de quais grupos terão mais sucesso em levar sua agenda para frente, num futuro imediato.

Dentro da mesma comunidade gay, os posicionamentos são diversos. No caso dos EUA, parece que entre as mais importantes divisões mantémse aquela já histórica: entre os mainstreamers e os que se autodenominam queers ${ }^{18}$ - quer dizer,

\footnotetext{
17 Basta lembrarmo-nos do furor causado alguns anos atrás pela inclusão no currículo do ensino primário de um livro que contava a história de uma menina que "tinha duas mães."

18 Palavra da língua inglesa que era utilizada para referirse pejorativamente aos homossexuais, o termo foi reapropriado pelo movimento gay, à maneira de autoafirmação.
}

os que lutam para serem considerados "pessoas normais", e os que se vêem como pessoas que desafiam os termos da normatividade social. A persistente relevância desta divergência diz respeito ao paradoxo que envolve a questão das identidades sexuais no nosso momento, um paradoxo que não me parece tão diferente daquele que se observa em relação às identidades de gênero ${ }^{19}$. Como tentei demonstrar, o mesmo processo de constituição da moderna identidade homossexual (e também da sua contrapartida, a heterossexualidade, ou mesmo uma aparente posição alternativa da bissexualidade) surge profundamente marcado pelas relações de poder que identificamos como opressoras. Em outras palavras, a "identidade homossexual" pode, pelo menos em parte, ser entendida na sua qualidade de "produzida" por uma prática discursiva de identificação e controle. Portanto, poderíamos imaginar que o melhor seria livrar-nos dessas identidades, através da ação política, mas também da mesma "desconstrução" dos termos forjados no contexto de tal poder: des-construindo as categorias, de certa forma estaríamos des-construindo a realidade. De fato, para algumas pessoas, a liberdade de não precisar de uma "etiqueta", de não serem percebidas e identificadas a partir da forma que exercem sua sexualidade, é a liberdade almejada. Talvez, assim como para alguns, as categorias "homem" e "mulher" sejam construções baseadas numa identidade fictícia imposta sobre sujeitos sociais que não se reduzem e nem se resumem a elas ${ }^{20}$, poderíamos considerar que a contradição inerente a uma identidade sexual de certa forma já foi construída a partir da "ótica do poder".

Mas, por outro lado, não é só "o discurso" ou pelo menos, o discurso hegemônico - que constrói o sujeito. Como também vimos, houve um processo político de re-apropriação da identidade homossexual, por pessoas que assim reivindicam sua diferença, desafiando dessa maneira a heteronormatividade do poder. Nesse sentido, vemos que assumir uma identidade pode também ser compreendido como um ato de afirmação, até

\footnotetext{
19 Questão que tem gerado um debate considerável entre as grandes teóricas feministas da atualidade, como Susan Bordo e Judith Butler. Uma tentativa minha de discutir este debate encontra-se no meu artigo, Adelman (1999).

20 Ver esta discussão em Susan Bordo (1994).
} 
de rebeldia, criando laços de solidariedade com outros que a compartilham e aceitando o desafio de ir além de uma "democracia da tolerância", para uma (mais) verdadeira desconstrução de todas as formas de opressão social institucionalizadas.

Recebido para publicação em 20 de agosto de 1999.

Míriam Adelman (miriamad@ @oruja.humanas.ufpr.br) é Professora do Departamento de Ciências Sociais da Universidade Federal do Paraná (UFPR).

\section{REFERÊNCIAS BIBLIOGRÁFICAS}

ADELMAN, M. 1999. O gênero na construção da subjetividade : re-pensando a "diferença" em tempos pós-modernos. Revista Humanas, Curitiba, n. 7-8, p. 9-22.

BORDO, S. 1994. Feminism, Postmodernism and gender skepticism. In: HERMANN, A. C. \& STEWART, A. J. Theorizing Feminism: parallel trends in the humanities and Social Sciences. New York: Westview Press.

BRISTOW, J. 1997. Sexuality. London: Routledge.

CLAUSEN, J. 1997. Beyond gay and straight : understanding sexual orientation. Philadelphia : Chelsea House Publishers.

D'EMILIO, J. 1983. Sexual politics, sexual communities : the making of a homosexual minority in the United States, 1940-1970. Chicago : University of Chicago Press.

D'EMILIO, J. \& FREEDMAN, E. 1988. Inti- mate matters : a history of sexuality in America. New York : Harper and Row Publishers.

GARBER, M. 1997. Vice-versa : bissexualidade e o erotismo na vida cotidiana. Rio de Janeiro : Record.

GRONEMAN, C. 1994. Nymphomania : the historical construction of female sexuality. Signs, p. 337-367, Winter.

HALL, S. 1998. A identidade cultural na pósmodernidade. Rio de Janeiro : DP\&A.

RUBIN, G. 1998 Thinking sex : notes for a radical theory of the politics of sexuality. In: NARDI, P. M. \& SCHNEIDER, B. E. Social perspectives in lesbian and gay studies. London : Routledge.

ZARETSKY, E. 1976. Capitalism, the family and personal life. London : Pluto Press. 